\title{
FRIDA KAHLO E VIRGINIA WOOLF: ESCRITA E PINTURA COMO CONSTRUÇÃO DE UMA PERSONA
}

Maria Aparecida de Oliveira

Resumo: Frida Kahlo tornou-se um ícone, um mito, uma mania, assim como a sua obra passou a ser reconhecida e celebrada mundialmente. Sua arte revela sua sensibilidade e, também, o sofrimento de seu corpo tragicamente mutilado, após o acidente que determinou sua vida inteira. O principal questionamento nesse trabalho é como podemos compreender o processo de pintura/escrita/vida de Frida Kahlo e de Virginia Woolf, como um processo de construção de uma persona, que está intrinsicamente ligada à sua pintura e à ficcionalização de seu diário, de modo a determinar uma das facetas que gostaria de mostrar ao público. Ao longo do trabalho, a intenção é aproximar Frida Kahlo da escritora Virginia Woolf, percebendo de que modo elas convergem e se distanciam. Enquanto mulheres e artistas ambas estavam revolucionando a cena artística e literária de seu país e deixaram marcas profundas que hoje impactam muitas mulheres em todo mundo. Em relação à fortuna crítica sobre Frida Kahlo, o trabalho conta com os pressupostos de Herrera (1991), Lowe (2005), Stellweg (1992), Toro (2013), Franco (2007). Sobre a construção da imagem de Virginia Woolf, o trabalho está baseado nas concepções de Jane Marcus (1987), Brenda Silver (1999) em Virginia Woolf, an Icon.

Palavras-chave: Frida Kahlo. Virginia Woolf. Diários. Escrita de si.

Abstract: Frida Kahlo became an icon, a myth, a mania, and her work became known and celebrated worldwide. Her art reveals her sensibility and also the suffering of her tragically mutilated body, after the accident which determines her whole life. The main aim of this paper is to comprehend Frida Kahlo's process of painting/writing/ life as a process of self-construction of a persona, which is intrinsically linked both to her painting and the fictionalization of her diary, trying to determine one of the facets she wanted to show her audience. In this work, the intention is to approximate Frida Kahlo to the writer Virginia Woolf, trying to understand how they converge and how they differ. As women artists, both were revolutionizing the artistic and literary scene 
of their countries and they both left a deep impression which impacted many women all over the globe. Concerning the criticism of Frida Kahlo, the paper is based on the assumptions of Herrera (1991), Lowe (2005), Toro (2013), Franco (2007). On Woolf's image construction, the paper is based on the conceptions of Jane Marcus (1987) and Brenda Silver (1999) in Virginia Woolf, an Icon.

Keywords: Frida Kahlo. Virginia Woolf. Diaries. Writing the self.

\section{INTRODUÇÃO}

Virginia Woolf nasceu em 1882 e suicidou-se no Rio Ouse em 1941. Frida Kahlo nasceu em 1907 e morreu em 1954, suspeita-se que ela haveria cometido suicídio. Enquanto Woolf escrevia, Kahlo pintava sua vida e escrevia seu diário, o qual iniciou em 1944, mas que também contém fragmentos de anos anteriores. Woolf pintava seus quadros literários em seus diversos retratos de personagens imaginários. Para Frida Kahlo, a pintura era um modo de sobrevivência, um modo de se recuperar psicologicamente de tantas cirurgias a que foi submetida em toda a sua vida. Para Woolf, a escrita era uma forma de superar as diversas batalhas de sua crise mental. Após cada publicação de um romance, uma nova crise surgia e com ela, uma nova ideia de um novo romance.

Frida Kahlo demonstra uma grande contradição, ao mesmo tempo em que ela utiliza uma máscara de uma mulher forte e imbatível, ela também revela uma grande vulnerabilidade, seu sofrimento, seu corpo mutilado e seu 
coração partido. Enquanto seu rosto se mantém forte, seu olhar determinado, seu corpo firme e ereto em suas fotografias. Em suas pinturas, observamos sua coluna partida, seus olhos repletos de lágrimas e seu corpo sendo atacado por vários espinhos. O leitor/espectador dessa obra identifica-se imediatamente, passando por um momento de catarse, ele sofre com Frida ao acompanhar seu sofrimento e, assim, é levado a questionar as partes mais profundas e obscuras de seu próprio ser.

Frida Kahlo nasceu no dia 06 de julho de 1907, mas na verdade ela considera seu nascimento no ano da Revolução Mexicana em 1910. Na infância, Kahlo contraiu poliomielite e em 1926, quando ela tinha 19 anos, ela sofre um terrível acidente que marcaria toda a sua vida e seu corpo. Hayden Herrera (1991), no livro Frida Kahlo: The Paintings, afirma que Frida pintou seu próprio mundo, no qual ela estava enclausurada, no seu começo e no seu fim, o criador e a criatura nela mesma e, ao mesmo tempo, a criadora e a destruidora. Hayden nos apresenta uma sequência de pinturas, como a própria narrativa de vida de Frida Kahlo. Em My birth and I, a cabeça de um bebê que poderia ser Frida, ela mesma, mas a cabeça da mulher coberta pelo lençol, traz uma dupla conotação: por um lado, poderia ser a artista 
dando vida a si mesma, num processo de criatividade contínua e permanente, sendo ela sua criadora e criatura. Mas, por outro lado, pode ser a representação da perda materna, indicando a sensação de abandono e desamparo, sendo a morte um tema constante na pintura e nos diários de Frida Kahlo. Sara Lowe (2005) ao analisar o diário de Frida Kahlo, observa como a artista estava sempre muito consciente da forma como se apresentava ao mundo, nesse processo de invenção e reinvenção de si mesma. Lowe aponta que:

Kahlo, ever conscious of how she presented herself to others, comments here - she 'gave birth to herself' - a remark with numerous allusions. Through the act of painting Kahlo established herself as an artist, and her many self-portraits are manifestations of her need to demonstrate the various aspects of her self. (LOWE, 2005, p. 228)

Na sequência temos a pintura My Nurse and I, Frida pinta a si mesma como bebê, mas com a sua face de adulta. Sua babá a alimenta, mas aqui também a interpretação é dupla, Frida alimenta- se da sua própria arte, ressignificando a imagem canônica da virgem com o bebê, o que poderia representar uma ideia de perda e separação, pode ser entendida com um símbolo de fé na sua força da sua ancestralidade, num jogo de identificação e de alteridade, em que uma alimenta a outra. Assim como a pintura Two Fridas, em que se percebe 
uma reconciliação consigo mesma, acolhendo suas heranças ancestrais, em uma relação constante de simbiose.

\section{IMAGENS DE FRIDA KAHLO E DE VIRGINIA WOOLF}

Sobre as imagens de Frida Kahlo veiculada por vários fotógrafos, Carla Stellweg em Frida Kahlo. The camera seduced, (1992) entende que:

For all of them (photographers), Frida, with an innate sense of her own image, molded her expression and arranged her body. What each photographer produced was the image of a woman with a well- defined identity, a person sure of herself, without fear of showing her place in life and proud to be where she had reached. (STELLWEG, 1992, p. 105)

Nesse sentido, podemos comparar as duas fotografias de Gisele Freund, tanto de Frida Kahlo como de Virginia Woolf. A última, como consta em seu diário, odiava posar para fotografia ou para pintores. Ela detestava o escrutínio do olhar do outro, sentindo-se examinada, evita o olhar, se mantém evasiva. Em 1939, Victoria Ocampo convida Gisèle Freund para fotografar Virginia Woolf, que registra em seu diário sua grande aversão ao fato.

Freund, por outro lado, expressa em seu livro, outra atitude de Woolf, que havia trocado de vestido para posar para as fotos e que lhe presenteou com um album de 
retratos de sua tia Julia Cameron, publicado pela Hogarth Press. Sobre Woolf, Freund (1985) observa que:

Frail, luminous, she was the very incarnation of her prose. She was fifty- eight years old when I photographed her, and her hair was turning gray. She was tall and slender, and the features of her face, simultaneously sensual and ascetic, were surprisingly beautiful. Her large, grave eyes in their deep sockets were surmounted by prominent eyebrows. Her mouth, with its full, soft lips, had an expression of touching sadness. The fine, straight nose seemed devoid of flesh. This face, as though bathed in an inner light, reflected both the sensitivity of a visionary and a great sincerity. A captivating atmosphere emanated from the entire person of this extremely reticent woman. (FREUND,1985, p. 96)

Ao contrário de Woolf, que abominava posar ou ser fotografada. A pintora acostumou-se às fotografias tiradas pelo pai, Guilhermo Kahlo, que era fotógrafo. A artista encara a câmera, entra no jogo, cria uma persona, apruma o corpo, mostra-se forte, destemida, por vezes desafiadora, apesar do corpo partido. Depois de ter fotografado Woolf, em 1939, a fotógrafa judia Gisèle Freund parte para a Argentina, onde encontra Victoria Ocampo. Depois de viajar por outros países da America do Sul, como Uruguai, Chile, Equador, Freund volta a França em 1946, depois do final da guerra. Em 1950, 
ela aceita o convite de Alfonso Reyes para ir ao México, onde fotografa várias celebridades, dentre elas, Frida Kahlo. Sobre Frida, Gisèle Freund, citada por Gérard de Cortanze (2013) declara "She was a formidable being, but in great distress. In the last years of her life, she was constantly swallowing a wide assortment of pills. Not only because of the physical pain due to her terrible tram accident, but also because she was a deeply conflicted being" (CORTANZE, 2013, p. 19).

Freund fotografou Kahlo em diversas situações: em seu jardim, cercada por plantas e flores, com um xale vermelho e um vestido branco; em sua cama, em um aspecto sereno, mas que expressa a dor que ela estava sentindo naquele momento; com seu médico Dr. Juan Farill, ao lado do autorretrato em que ela pinta; pintando o retrato de seu pai; Frida Kahlo olhando a câmera com um sorriso delicado terno, quase pueril, que é a capa do livro; Frida Kahlo fumando, ao lado de uma escultura pré-hispânica, em seu jardim. Em alguns momentos, percebe-se que a cena é programada para as fotografias, em outras há uma espontaneidade, em que a artista está agindo naturalmente, alimentando os gansos, pintando, fumando ou deitada na cama. Todos esses momentos capturados pela câmera de Gisèle Freund são sem sombra de dúvida, momentos históricos. Os 
anos de 1950-1952 foram anos bastante tortuosos para a pintora, ela passou a maior parte do tempo no hospital, sendo submetida a diversas cirurgias em sua coluna. Frida Kahlo pressentia que não Ihe restava muito tempo, passa, portanto, a escrever cartas a diversos amigos, inclusive à Freund, mas essas se perderam no meio do caminho. Como leitores/espectadores dessa cena, pode-se observar diversas facetas da personalidade de Frida Kahlo: seu momento de vulnerabilidade, de fragilidade, mas também a sua força, sua garra, sua determinação em continuar pintando, apesar das fortes dores. Em outro momento, Gisèle Freund afirma:

A heroic, nearly legendary figure, she sat in her wheelchair year after year painting terrifying canvases in the surrealist manner for which she became famous. She had a strange, moving beauty, which she had inherited from a Mexican mother and a German father, on top of that, she was very witty and had a lively intelligence. (FREUND apud CORTANZE, 2013, p. 89)

Pode-se pensar nas fotografias e nos autorretratos como uma forma de construção da sua persona. Maria Teresa Franco (2007), em "Frida Kahlo: Self-portrait in ink" analisa o quadro Self- Portrait wearing a Velvet Dress de 1926, para ela esse seria o início desse processo de construção, em que Frida expressa seus sentimentos, sensações e 
impressões, que ela tinha de si mesma, de suas memórias e de sua infância, um processo muitas vezes baseado no sofrimento que engloba sua juventude, sua maturidade e a deterioração de seu corpo. Assim, pode-se compreender sua obra como uma autobiografia, que ao invés de escrita, é uma autobiografia pintada. Nesse quadro, a luz que se projeta no pescoço e no colo contrasta com o negro que emoldura sua face, o decote sugere um mistério e uma sensualidade que se confirma no olhar firme, também emoldurado pelas negras sobrancelhas que se juntam em forma do voo de um pássaro, projetando um nariz também alongado e fino, seguido por uma boca bem delineada em um tom rubro que combina com o veludo do vestido. As mãos alongadas escondem, revelam e convidam. Olhar e ouvidos atentos, cabelos negros bem ajustados em sintonia com o negro da sobrancelha e do fundo preto. A figura está elegantemente vestida e demonstra um ar de mistério, encanto, inteligência e sagacidade.

Nesse processo de autoconstrução, os vestidos e joias mexicanas de Frida Kahlo têm um duplo significado, os quais podem se referir às suas raízes; ou podem ser uma máscara de seu corpo sofrido, que também é uma metáfora do próprio país. Enquanto refletia sobre seu 
próprio sofrimento, solidão, dor e diferença, ela também refletia a dolorosa busca por uma identidade nacional no México pós-revolucionário. Representando seu corpo ferido, ela também representa a ferida aberta do México no corpo social, econômico e político baseado em injustiças e desigualdades de gênero, parte de uma época que ela conhecia profundamente. Trataremos mais adiante sobre a relação de Frida Kahlo com o México.

Em relação à Virginia Woolf, há vários retratos sobre a sua imagem, dentre eles, o famoso quadro de Vanessa Bell, em que ela retira os aspectos faciais, mas sabemos que se trata de Virginia Woolf. Duncan Grant, famoso pintor do Bloomsbury Group, também tem um quadro de Virginia ainda como Virginia Stephen, quando ela ainda não havia se casado com Leonard Woolf. Em relação às fotografias também há diversas fotografias de Virginia Woolf, fotografada por famosos fotógrafos, que fizeram registros históricos da escritora. Sobre o processo de construção da imagem de Virginia Woolf, Brenda Silver analisa como ocorre tal processo em seu instigante livro Virginia Woolf Icon, no capítulo "Starring Virginia Woolf", a autora examina as fotografias mais veiculadas na mídia. A foto glamorosa de Woolf para a revista Vogue, em que encontramos uma 
Woolf quase como uma celebridade, parte da sociedade britânica. Em 1934, Woolf é fotografada por Man Ray, representante da avant-garde de Paris, estava mais preocupado com o rosto de seus objetos do que na fama que eles representavam. E em 1939, Woolf é fotografada por Gisèle Freund. Além disso, em 1972 quando é lançada a biografia de Woolf, escrita por seu sobrinho Quentin Bell, a imagem utilizada é uma fotografia de G. C. Beresford, uma jovem Woolf de vinte anos de idade, frágil, éterea e apolítica. Sobre a resistência de Woolf em ser fotografada, Silver justifica que:

Her uneasiness about her public persona had some justifications; when Beaton appropriated her photographic image for his ghostly description in The Book of Beauty, he anticipated what became a major aspect of her construction as icon: the verbal portraits of Virginia Woolf that read her character in and through her photographs. (SILVER, 1999, p. 135)

Todas essas fotografias, incluindo também aquelas tiradas pelo Lenare Studio, contribuíram para o processo de construção da imagem de Woolf como um ícone, segundo Silver (1999). É claro que esse processo envolve uma rede complexa de significados de sua imagem, que por vezes pode ser bastante contraditória. Em contraposição a essa 
imagem de fragilidade, Woolf muitas vezes é associada a uma figura aterrorizadora, a ideia de medo ficou atrelada à sua imagem devido à peça de Edward Albee, Who is Afraid of Virginia Woolf, assim como, seu feminismo. Para Jane Marcus (1987), Woolf, também, se tornou um ícone do feminismo literário, nos estudos feministas, assim como na cultura política nos Estados Unidos. Mas, para Marcus, sua imagem tem sido super- representada, como ela aparece nas livrarias, em camisetas, marcadores de texto, enfim como uma mercadoria, uma commodity cultural e intelectual. A imagem de Woolf tem sido modelo para a loucura feminina nas décadas de 70 e 80, ou nas narrativas de anorexia, abuso infantil, tanto como vítima ou santa.

\section{DIÁRIO COMO CONSTRUÇÃO DE UMA PERSONA}

Frida Kahlo como escritora é uma outra faceta do seu trabalho, ao qual não tem sido dado grande atenção. É claro, que ela preferia o pincel à caneta, mas por meio do diário de Frida, temos uma outra forma de expressão. Ele contém poemas, narrativas, baladas, versos fragmentados, cartas. Podemos compreendê-lo como um exercício literário, em que Frida também estava preocupada com a forma, mas jamais ela se consideraria uma escritora. Ela utiliza seu diário para expressar sua mensagem e ela 
o faz da maneira mais profunda, do alto da sua condição mais humana, demonstrando suas dores, sua fragilidade, sua vulnerabilidade, suas alegrias e descontentamentos. Pode-se compreender seu diário como uma construção de sua persona, como ela encara seu sofrimento e como lida com a morte. Por outro lado, suas cartas demonstram sua relação de amor/ódio por Diego Rivera, como resultado dessa relação tempestuosa, a loucura aparece como uma das facetas/máscaras. Como se questiona Hayden Herrera em sua biografia de Frida Kahlo, a artista seria uma vítima trágica ou uma sobrevivente heroica?

Alfonso de Toro (2013) em seu artigo “Frida Kahlo's Transpicturality Revisited: Transmedial Dispositives, Representation, and Anti-Representations" nos oferece um breve panorama, teórico e analítico, das estratégias de transmedialidade relacionadas ao trabalho de Frida Kahlo. Além disso, ele nos mostra como o trabalho de Frida Kahlo está conectado com a tradição europeia de vanguarda, utilizando os conceitos de Artaud, Derrida e Deleuze. Por um lado, Kahlo rompe com a tradição, declara Alfonso de Toro, ao pintar as entranhas e partes desmembradas dos corpos, assim como os genitais e zonas erógenas de forma cruel e grotesca. Por outro lado, ele a coloca dentro da tradição 
europeia, ao lado de artistas como Antonin Artaud, Salvador Dali, Max Ernst, Giorgio de Chirico, René Magritte, Francis Bacon. O crítico conclui que:

Her work is definitely not only the expression and representation of her life, but a very intensive debate with the avant-garde of her time, and a dialogue with older painters. Her work is an admirable recodification of this avant-garde and of the painting tradition, the creation of a new form of expression. That is why the work of Kahlo is Always placed at the interfaces of cultures, arts schools, poetics, and normative genres; she is, on the contrary, highly transcultural and transmedial like the multiple pictural references that the last example, Self portrait on the Borderline Between Mexico and the United States, 1932. (TORO, 2013, p. 345)

Tendo esse panorama da obra da pintora mexicana, antes de iniciarmos a análise do diário de Frida Kahlo, a primeira questão que surge é qual era o contexto em que vivia como artista, o que ocorre para que ela inicie a escrita de seu diário. A artista começa seu diário em um período em que sua saúde começa a declinar, durante toda a sua vida, ela passou por mais de vinte operações. Em 1944, após uma dessas cirurgias, a recomendação médica era de repouso total, assim, ela inicia seu diário. Antes disso, a década de 1930 e os anos iniciais da década de 1940 representaram um 
período bastante produtivo de sua vida. Na verdade, Frida Kahlo começa a pintar em 1926, logo após o acidente que marca sua vida dramaticamente. Ela casa-se em 1929 com Diego Rivera, famoso pintor e muralista, logo os dois viajam para os Estados Unidos, onde Rivera recebe uma subvenção para pintar murais em Detroit. A partir de então, Frida Kahlo começa um período extremamente produtivo, com exposições nos Estados Unidos e na França, com a ajuda de André Breton, grande representante do surrealismo francês. Dentre as exposições mais importantes, pode- se destacar: 1. Julien Levy Gallery em Nova Iorque, com prefácio de André Breton, em 1938; 2. Galerie Renou\&Colle, na França, com a contribuição de Marcel Duchamp em 1939; 3. Exposição Internacional do Surrealismo, organizada por Breton, na Galeria de Arte Mexicana, em 1940; 4. Contemporary Mexican Painting and Graphic Art no Palace of Fine Art em São Francisco; 5. Museu de Arte Moderna de Nova lorque; 6. Exposição "Modern Mexican Painters" do Instituto Moderno de Arte de Boston; 7. Em 1942, tem seu trabalho exposto em duas exposições "20th Century Portraits" no Museu de Arte Moderna e "First Papers of Surrealism"; 8. Em 1943, Exposição "Exhibition by 31 Women" at Peggy Guggenheim's Art of this Century Gallery, em Nova Iorque. 
Além disso, Frida Kahlo também atuou como instrutora na Escola de Pintura e Escultura do Ministério da Educação do México, com a declínio de sua saúde, ela mantém as aulas em casa, em Coyoacan, seus alunos mais fiéis são conhecidos como "Los Fridos", Fanny Rabel, Arturo Garcia Bastos, Guilhermo Monroy e Arturo Estrada (KAHLO, 2005, p. 290-291).

Há diversos temas abordados por Frida em seu diário, dentre eles, a morte, a loucura, o sofrimento. Alguns críticos apontam que parte do sofrimento de Kahlo provém de sua complexa relação com Diego Rivera. Apesar de seu amor, Frida Kahlo sabia que não podia manter nenhuma ilusão por ele, ela escreveu em 1949: “Diego has never been and never will be anyone's husband". Frida Kahlo pintou vários retratos de Diego Rivera, em "Portrait of Diego", ela o segura como um bebê, com um terceiro olho, que denota o olhar intuitivo do pintor, enquanto os dois são abraçados pelo universo. Esse retrato conecta-se intimamente com o poema que ela escreve a ele:

I am the embryo, the germ,

The first cell which $=$ potentially $=$

Engendered him

I am him from the most primitive...

And the most ancient cells,

That with time became him. (KAHLO, 2005, p. 235) 
O poema começa com total entrega e como um devaneio, como no quadro "Portrait of Diego", Kahlo enxerga-se como genitora de Diego Rivera. Hayden Herrera revela que por muitas vezes a pintora assume o papel de mãe, mas no poema seguinte, Kahlo vai além da maternidade e se projeta como a célula germinal que engendra Diego, de maneira mais primitiva e mais antiga, ao passo que ela se torna ele. Essa simbiose ocorre tanto em outros poemas, como em outros quadros também. Kahlo pinta Diego excessivamente, assim, como ela também figura nas telas do pintor, como parte da revolução, como veremos mais adiante. Em seguida, Diego não é o começo, mas o filho, o pai e mãe, o namorado, o amante, o amigo e o marido. Mas, ao final, ela sabe que não o possui, pois ele pertence apenas a ele mesmo:

$$
\begin{aligned}
& \text { Diego beginning } \\
& \text { Diego constructor } \\
& \text { Diego my baby } \\
& \text { Diego my boyfriend } \\
& \text { Diego painter } \\
& \text { Diego my lover } \\
& \text { Diego "my husband" } \\
& \text { Diego my friend } \\
& \text { Diego my mother } \\
& \text { Diego my father } \\
& \text { Diego my son } \\
& \text { Diego = me = } \\
& \text { Diego Universe }
\end{aligned}
$$


Diversity within unity.

Why do I call him My Diego?

He never was nor ever will be mine.

He belongs to himself. (KAHLO, 2005, p. 235)

Outro aspecto fundamental, tanto na escrita, quanto na pintura de Frida Kahlo é a maneira como ela lida com seu sofrimento, em relação ao acidente que sofreu em 1926, de certa forma ligado a esse sofrimento físico está o tema da loucura e da morte. Vejamos em seguida, com a artista reflete sobre esse tema e como ele aparece reconstruído na sua arte, seja ela escrita ou pictórica. 0 Quadro "Broken Column" realizado em 1944 seria o quadro mais emblemático para expressar o sofrimento como fruto das diversas operações devido ao acidente, o colete para ajustar seu corpo, nele a artista pinta os símbolos do comunismo, uma foice e um machado; as copiosas lágrimas retratam a dor, mas o olhar firme demonstra a força e a resignação de Frida Kahlo.

Frida Kahlo pintou, em seu diário, o "Portrait of Neferúnico - Founder of Lokura", outro tópico recorrente na sua escrita, com seus próprios traços como se ela fosse a própria loucura ou como se ela a engendrasse. Como explica Lowe, o terceiro olho representa o lado intuitivo de Frida, sempre tão representado ao longo de suas obras. 
Outra característica desse retrato seria a androginia da figura, característica que se repete também em outros quadros. Para Frida Kahlo, a loucura não é apenas um aspecto negativo, mas sobretudo, um aspecto da liberdade, uma libertação dos padrões repressivos sociais em um momento ela declara em seu diário:

I wish I could do what ever I liked - Behind the curtain of "madness", then: I'd arrange flowers, all day long. I'd paint, pain, love and tenderness, I'd laugh as much as I feel like at the stupidity of others, and they would all say: Poor thing! She's crazy. (above all I'd laugh at my own stupidity). (KAHLO, 2005, p. 242)

Apesar de todo o sofrimento de Frida Kahlo, ela tinha um grande senso de humor e podia encontrar momentos de alegria nas pequenas cenas do dia a dia, como os cães brincando com um fio, o desenho produzido a partir dessa cena, resulta num quadro bastante rizomático expressando a ideia de um labirinto. O surreal surgia das cenas mais cotidianas e eram acrescentados a elementos insólitos, inéditos, peculiares e singulares. Sobre o riso, Frida Kahlo expressa:

There is nothing more precious than laughter. It is strength to laugh and lose oneself to be light. Tragedy is the most Ridiculous thing "man" has, but I'm 
sure that animals suffer, and yet they do not exhibit their "pain" in "theatres" neither open nor "closed" (their" homes") and their pain is more real than any image that any man can "perform" $x x x x$ of feel as painful. (KAHLO, 2005, p. 239)

O riso aqui é uma maneira de lidar com ambos, com a loucura e com a dor. Frida Kahlo evita assumir uma posição de vítima, a tragédia que ela tanto critica. Mas nesse poema pode-se perceber a consciência de Frida Kahlo em relação à performance do seu sofrimento e como ela o teatraliza para seu público. A melhor maneira seria rir da sua própria tragédia, de seu próprio sofrimento, da sua própria estupidez e da estupidez alheia. Virginia Woolf também reconhecia o valor subversivo do riso e do humor, como demonstrado em Orlando, a biography (1928), em Flush, a biography (1933) e Freshwater (1935). Por outro lado, Woolf também soube expressar seu próprio sofrimento em "On being III", pensando nos limites da linguagem para comunicar as dores do corpo. Hermione Lee na "Introdução" de On Being IIl afirma que:

Illness is one of the main stories of Virginia Woolf's life. The breakdown and suicide attempts in her early years, which can be read as evidence of manic depression (though that diagnosis has been hotly contested) led, in the thirty years of her 
adult writing life, to persistent, periodical illnesses, in which mental and physical symptoms seemed inextricably entwined. In her fictional versions of illness, there is an overlap between her accounts of the delirium of raging fever (Rachel in The Voyage Out), the terrors of deep depression (Rhoda in The Waves), and the hallucinations and euphoria of suicidal mania (Septimus in Mrs. Dalloway). (LEE, 2012, p. XIV)

O sofrimento em Woolf é uma realidade, assim como na escrita e na pintura de Frida Kahlo. Enquanto Kahlo expressa esse sentimento por meio da pintura, Woolf o reelabora na criação de seus personagens, como demonstra Hermione Lee. Outro desenho de Frida que também expressa seu sofrimento e a decadência de sua saúde física seria "I am disintegration" (KAHLO, 2005, p. 225), o qual representa um desenho surreal, por um lado há a figura de um Minotauro em um corpo feminino. Seguindo a ideia de Picasso, o Minotauro representaria uma força instintiva incontrolável, há uma divisão e não sabemos se a cabeça do Minotauro seria de um homem ou de uma mulher. Frida Kahlo sempre pinta figuras andróginas, seres hermafroditas, que representam uma dualidade, mas também uma ambiguidade sexual. Do lado direito, o rosto de uma figura andrógina, a partir da cabeça sobressai um pé e um seio. Do lado esquerdo, há a cabeça do Minotauro, em um corpo feminino, bipartido e 
ao lado, a figura de Frida em miniatura, como se fosse uma boneca ou uma marionete, caindo do alto de uma coluna grega, desintegrando-se aos poucos, uma mão e os olhos e a cabeça caem ao lado do corpo.

O sofrimento de Frida Kahlo após 1944 tornou-se uma constante, o uso de medicamentos para aliviar a dor, resultava também em um processo alucinatório, como se ela estivesse fora de órbita. A partir desta data, Hayden Herrera (2002) percebe que Frida Kahlo passa a pintar mais natureza morta, do que retratos, os quais exigiam mais tempo em frente ao espelho e maior dedicação e esforço. Frida Kahlo utiliza um jogo linguístico com a expressão "natureza morta", em inglês "still life". Nesse período, Kahlo passava muito tempo na cama, ela mesma se sentia em estado vegetativo, ou como se sua vida estivesse "still", em suspenso. Sobre esse desenho, Sarah Lowe (2005) percebe que:

This image precedes a period during the early 1950s when she made thirteen paintings in less than four years. As her health declined, she ceased painting self-portraits, which required hours staring into a mirror, and turned instead to painting fruits and vegetables. Her painting Naturaleza Viva, from 1952, suggests that her endless days in bed led her to think of herself as a vegetable: the title translates as "living life" (or "living nature". (LOWE, 2005, p. 233) 
Em outros momentos, Frida Kahlo utiliza a expressão "natureza viva", ao invés de "natureza morta", ela utiliza em momentos mais otimistas, a expressão "Viva a vida". Durante esse período, a morte torna-se uma presença constante em sua obra, Frida encara a morte sem medo, usando apelidos para se referir a ela. Há de fato na cultura mexicana uma forma de celebrar a morte, de dançar com ela, a ponto de dizermos que a pintora estava a todo momento dançando com a morte. Em seu quadro "A very still "still life", a exemplo de Van Gogh e seu quadro de girassóis, Frida personifica tanto o vaso, quanto as flores, conferindoIhe feições humanas, com uma mão ao lado, que lembra um saco de grãos. O efeito é insólito e peculiar, típico dos pintores surrealistas e mantém um certo grau de humor. Ao criar tal efeito, Frida Kahlo rompe com a tradição deste gênero "natureza morta", criando a ambiguidade entre vida/morte ou dando vida àquilo que devia estar morto. Sua natureza morta nunca está completamente morta, ela sempre inclui um elemento com vida, seja uma pomba e um sol animado com raios escaldantes, um papagaio, um pássaro, um de seus cachorros ou macacos, com bandeiras do México e frases "Viva a Vida". Nesse sentido, Herrera observa que Frida Kahlo politiza sua natureza morta, subvertendo mais uma vez um gênero da pintura. Ao dar 
vida à natureza morta, Kahlo desestabiliza nosso olhar, nos tirando da nossa zona de conforto e nos levando a refletir sobre temas tão caros como morte/vida.

Outro quadro que nos chama muito a atenção devido ao seu aspecto fortemente apelativo seria a imagem que aparece na capa do diário e apresenta a figura de Frida Kahlo com asas, os seios a mostra e o corpo coberto por folhas aparentemente em chamas. Frida aparece de forma bastante fragilizada e diante da figura há um diálogo "Are you going?" questiona e ela responde "No" e abaixo "Broken wings". Essa imagem nos parece bastante significante, nela pode-se ler a impossibilidade do movimento, as asas quebradas podem denotar a perna, como membro de mobilidade, a incapacidade de se mover e se referem a amputação da perna da pintora. Por vezes, as asas podem ser comparadas à imaginação da pintora, se colocarmos ao lado dessa imagem, uma outra que traz a imagem do pé de Frida dele saindo ramos e abaixo a seguinte frase: "Feet what I do I need them for If I have wings to fly" (2005, p. 274). Para Sarah Lowes, a referência às asas seria um chamado aos anjos ou a alguma intervenção divina. Entendemos as asas como seu poder imaginativo e criativo, mesmo com os pés rompidos, quebrados, removidos, a pintora ainda pode 
confiar em seu poder para criar livremente. No entanto, em "Alas Rotas", vemos que esse poder está interrompido, o corpo partido reflete a impossibilidade de usar seu poder imaginativo. Seus pés são extremamente emblemáticos e aparecem, também, em "What water gave me", que será analisado em seguida.

Hayden Herrera (2002) observa que as diversas e desnecessárias cirurgias, em muitos casos, eram uma forma de autossabotagem e, também, de narcisismo, uma forma de chamar a atenção:

Each operation brought her admiration and sympathy and most important, the attention of Diego. One of her doctors said that her health depended on her feelings about Rivera. When he was away or she felt abandoned by him, she would precipitate a crisis. When he was at her side, she recovered. This pattern must have had its origin in her childhood, when she had polio and her father took it upon himself to restore his favorite daughter to health. (HERRERA, 2002, p. 194)

A relação de Frida Kahlo com analgésicos e morfina para atenuar a dor era bastante complicada. Sob o efeito dos remédios, entrava em um estado quase maníaco, afirmando que ela poderia operar sua própria revolução (HERRERA, 2002, p. 197). Contudo, sem os remédios entrava em um período de forte depressão, perdendo a 
alegria e o entusiasmo, que Ihe eram tão peculiares. Seu estado oscilava entre períodos de excitação e de depressão e ansiedade:

August 1953. It's certain they are going to amputate my right leg. Details I don't know much, but opinions are very reliable. Dr. Luis Mendes and Dr. Juan Farill. I am very very worried, but at the same time I feel it would be a relief. In the hope that when I walk again, I'll give what remains of my courage to Diego. Everything for Diego. (KAHLO, 2005, p. 277)

Esse fragmento do diário aparece junto a uma imagem bastante significativa do período de sofrimento para a pintora. A imagem parece dialogar com outras imagens como "Broken wings" e "Broken Column" e está meticulosamente bem construída, trabalhada nos mínimos detalhes. No lugar da cabeça há uma pomba e abaixo aparece escrito "The pigeon made mistakes. It made mistakes". Pássaros são sempre alegóricos na pintura e no diário de Frida Kahlo. Geralmente, eles simbolizam liberdade e paz. No lugar dos braços, são desenhadas asas, lembrando sua frase "Feet what I do I need them for If I have wings to fly" (KAHLO, 2005 , p. 274). A coluna vertebral é substituída por uma lança, ajustada à cintura por uma faixa. A perna direita é trocada por uma estrutura em espiral, que sustenta o corpo. Alfonso de Toro (2013, p. 326) aproxima essa imagem do 
diário de Frida Kahlo à pintura de Salvador Dalí. The Burning Giraffe, de 1936, e à pintura Minotauro, também de 1936. Ambas pinturas de Dali representam um corpo feminino fragmentado e destruído, com gavetas no lugar dos seios, sustento por uma estrutura. A figura do Minotauro, também utilizada por Picasso, representa a loucura ou os impulsos que não podem ser controlados. Em 11/02/1954, a cirurgia foi realizada, Frida Kahlo expressa em seu diário o sofrimento a que ela foi submetida:

They amputated my leg 6 months ago. It seemed to me centuries of torture and at times I nearly went crazy. I still feel like committing suicide. Diego prevents me from doing it in the vain belief that maybe he will need me. He has told me so and I believe him. But I have never suffered so much in my life. I'll wait a while. (KAHLO, 2005, p. 278)

Após a cirurgia, Frida Kahlo teve períodos de altos e baixos, de grande otimismo, mas também de muita dor e sofrimento, aos poucos foi recuperando a confiança em caminhar e em pintar. Ela estava grata a todos os amigos que a acompanhavam, mas tinha a certeza que sua jornada havia chegado ao fim e que não gostaria de voltar, como deixa claro Hayden Herrera em sua biografia:

When she succumbed eleven days later, her death was reported was being caused by pulmonary embolism, but, given her suicide 
attempts, many of Frida's friends believe that she killed herself. The last words in her journal would suggest as much "I hope the exit is joyful - and I hope never to come back - Frida". The diary's last drawing is a black angel rising, surely the angel of death. (HERRERA, 2002, p. 219)

No final de seu diário, Frida Kahlo tem a necessidade não só de escrever um resumo de sua vida, como pinta um novo quadro com a sua árvore genealógica. Em toda a sua obra, Frida Kahlo opera uma reflexão sobre ela mesma, sobre suas origens e seu lugar no mundo. No final de sua vida, ela queria tornar sua obra mais política, deixando seu legado ao mundo. Ela encontrava sua força em seus ancestrais, as ruínas mexicanas aparecem como uma metáfora para a sua própria vida.

\section{OS DIÁRIOS DE VIRGINIA WOOLF}

Enquanto Frida Kahlo retomou seu processo de escrita apenas em 1944, Virginia Woolf tem uma longa história com a escrita de seus diários. Seus primeiros ensaios datam de 1904, durante esse período ela também inicia a escrita de seu romance The Voyage Out, que somente será publicado em 1915. O primeiro volume de seus diários data de 1915 a 1919, momento da publicação de seus romances iniciais. O quinto e último volume refere-se aos anos de 1936 até 
o momento da sua morte em 1941. Contudo, no prefácio do primeiro volume, Virginia Stephen aos quinze anos já mantinha um diário, em 1897. Entre os anos de 1898 e 1915, Woolf tinha no mínimo cinco cadernos, mas ela manteve-se fiel à escrita dos seus diários com maior regularidade a partir de 1915, depois de seu casamento com Leonard Woolf, por volta da publicação de seu primeiro romance, The Voyage Out. Os diários de Virginia Woolf foram organizados por Anne Olivier Bell e o primeiro contém uma introdução de Quentin Bell, sobrinho de Woolf, casado com Anne O. Bell. Quentin Bell, na introdução do primeiro volume, previne o leitor dizendo que se pode considerar o diário como uma obra de arte, não igual, mas no mesmo patamar que seus romances The Waves ou To The Lighthouse.

Uma questão importante colocada por Quentin Bell é até que ponto se considera o diário como arte ou como um documento histórico. Virginia Woolf estava sempre dizendo a verdade em seus diários ou ela ficcionalizava como fazia em seus romances? Até que ponto há a dramatização de uma escrita do diário, pensando justamente na construção de uma persona pública? Woolf estava escrevendo para si ou tinha um leitor idealizado em mente? A esse respeito, Quentin Bell pondera: 
Virginia Woolf's reputation for truthfulness was not good. She was supposed to be malicious, a gossip, and one who allowed her imagination to run away with her. At least one of her friends, foreseeing the publication of her letters and of this diary, tried to warn posterity that it must not believe everything that she might tell it. (BELL, 1977, p. XIII)

Diante disso, deve-se lembrar que Virginia Woolf é uma escritora e que os retratos pintados/escritos de outras personalidades de seu tempo são também fruto de sua imaginação aguçada, não devemos, portanto, pensar que são a mais pura e verdadeira face da realidade, mas que contêm seus julgamentos e estão sujeitas à sua perspectiva, e esta nem sempre é confiável. Bell adverte que suas cartas são ainda mais exageradas pois Woolf tinha como objetivo entreter seu leitor. Interessante notar, por meio das advertências de Quentin Bell, o retrato de Virginia Woolf produzido por meio de seus diários, o leitor tem acesso a uma faceta de Virginia Woolf que normalmente ele encontra em seus romances, uma Woolf que é "malicious, a gossip one". Por outro lado, outras facetas de Woolf são demonstradas por meio de seus diários: uma mulher inteligente e interessante em contato com seus contemporâneos; uma mulher de uma mente afiada e aguçada, que de tempos em tempos sofria um colapso mental, após as muitas perdas sofridas ao longo de sua vida. 
A Writer's Diary foi organizado e editado por Leonard Woolf em 1953, o diário compreende um período de vinte e sete anos, durante os anos de 1915-1941, nele temos uma ideia das atividades de Woolf, de pessoas que ela encontrava, seus pensamentos sobre a vida, sobre ela mesma e sobre os livros que ela escrevia. Nesse sentido, os diários representam um vasto material para aqueles que querem se dedicar à crítica genética, pois eles oferecem matéria prima como a gênese do processo de construção de seus romances. Virginia Woolf registra em seus diários o que ela estava lendo, o que ela estava escrevendo, como surgem as primeiras ideias para um romance, como o livro é publicado, quantas cópias são vendidas, as opiniões de seus contemporâneos sobre os romances publicados; como ela reagia a tais críticas e como elas a afetavam e, por fim, como surgiam as ideias para um segundo livro, mesmo em meio às crises mentais. Além disso, o leitor tem acesso ao diálogo de Woolf com outros escritores, outros intelectuais, família e amigos sobre seus livros.

Moments of Being pode ser lido também como um diário ou a escrita de memórias de Woolf. Na primeira parte temos suas primeiras lembranças, narradas para seu sobrinho Julian Bell sobre as impressões de sua irmã, Vanessa 
Bell. Nesse momento, Woolf está tentando expandir suas habilidades como escritora, tentando equilibrar sua imaginação poética, com as convenções literárias. $O$ retrato produzido é uma Virginia Woolf ainda vulnerável, não tão segura com o público para quem ela está escrevendo. Há uma certa consciência de si mesma e do "eu" que ela quer projetar para o seu leitor, mas o resultado, como explica Jeanne Schulkind é a de uma jovem escritora como fruto da "Victorian tea table manner". Já em "Sketch of the past", Jeanne Schulkind aponta que:

"Sketch of the past" provides a sharp contrast with its easy, unaffected manner revealing an ego so unaware of itself that it appears almost impersonal. So confident she is now, so much a master of her material, that she need not even be bothered to decide on a form before beginning [...] The memoir is characterized by a flowing, ruminative expansiveness; it presents a consciousness which follows its own peculiar byways rather than a pre-ordained route as it ponders the meaning of reality and the mystery of identity. (SCHULKIND, 1985, p. 16)

Enquanto "The Memoir Club" encontramos uma Virginia Woolf mais madura, que confronta os valores vitorianos com aqueles do seu grupo Bloombury. A família é vista sob uma perspectiva histórica mais ampla, explica Schulkind, ao passo que todos vão encontrando seu caminho, Thoby em 
Cambridge, Vanessa na pintura e Virginia com a sua escrita. Já em "Am I a snob" o leitor se depara com uma Virginia Woolf do alto da sua fama, uma escritora estabelecida e reconhecida, em 1936. Woolf investiga a si mesma e seu meio, seus privilégios e as limitações da sua classe social. "Am I a snob" é mais um retrato de Virginia Woolf e ela mesmo contestando essa imagem. Enfim, em Moments of Being, demonstra todo um processo de desenvolvimento de Virginia Woolf no controle de sua escrita e procurando veicular uma imagem ao seu leitor que nem sempre é aquela que reconhecemos da romancista.

\section{FRIDA KAHLO E A REVOLUÇÃO}

Ao passo que Frida Kahlo ia perdendo a saúde, sua vida foi se resumindo à sua pintura, a Diego Rivera e à política. Essa última tornou-se uma parte significativa de sua vida. Declarando- se comunista, passou a se preocupar mais com o aspecto político de seus quadros e como eles poderiam contribuir de forma mais efetiva com o partido Comunista. Em muitos de seus quadros e fotografias pode-se notar tal inclinação, como por exemplo, em uma de suas fotos ela desenha Marx em seu colete e os símbolos comunistas, uma foice e um machado. Em outro quadro, ela escreve que o comunismo é a salvação para os doentes. 
Dina Comisarenco Mirkin (2007) no artigo "Moon, Sun, Me" concentra-se no valor da arte de Frida Kahlo. Ela observa que Frida está sempre tecendo diferentes níveis de significados, fios pessoais e sociais, revelando uma realidade complexa, que evoca aspetos psicológicos, históricos e políticos. Ela usou gêneros pictóricos tradicionais, como retratos, crônicas, alegorias e naturezas- mortas. Diferentes temas poderiam ser encontrados em suas obras: a construção do que é ser mulher, suas expectativas e preconceitos, maternidade, infertilidade, fidelidade/ infidelidade, sexualidade (hétero, homo, bissexualidade) e violência de gênero. Mirkin assegura que:

Frida's deliberate self-construction as a living icon of the Revolution and "Mexican identity" led the artist to develop a series of images crossing distinct pictorial genres alluding to the longsuffering, but strong, indomitable woman artist. [...] Together with her husband, renowned muralist, Diego Rivera, she was a key figure of the complex, bloody and heroic political history of postrevolutionary Mexico. (MIRKIN, 2007, p. 179)

Frida Kahlo estava pronta para se identificar com o oprimido, com aqueles que sofrem, com os rebeldes e se indignava diante das injustiças. Seu trabalho também poderia ser lido como uma autoconstrução do ícone da Revolução, da identidade mexicana, mas também, como retrato de 
seu sofrimento, de sua coragem e de sua força como mulher artista, que estava quebrando as fronteiras para se estabelecer no mundo das artes. Sua imagem criada por Diego Rivera, em seus murais, também ajudou na construção de Frida Kahlo como um ícone da Revolução.

In Marxism Will Give Health to the Sick, 1954, Frida, dressed in an orthopedic corset and clutching a red book that must be Marx's Capital, is the victim saved by the miraclemaking saint, Karl Marx. Two enormous hands, one with an extra eye signifying wisdom, descend from the vicinity of Marx to support Frida so that she can cast aside her crutches. Another hand projects from Marx's head and strangles an American eagle, which is a caricature of Uncle Sam. Beneath the eagle rivers run red and an atomic bomb explodes. The other side of Marx's head is touched by a peace dove that hovers protectively over both Frida and a globe dominated by the Soviet Union, where the rivers are blue. Until 1954, Frida had painted only one quasi-political painting. (HERRERA, 2002, p. 215)

Suas pinturas, também, revelam o México pósrevolucionário, mostrando visões nacionalistas e suas conexões com os povos nativos e também suas conexões políticas nos círculos intelectuais da época. Rosa Casanova em seu texto "Images and Impressions of an Icon" 2007 ("Imagens e impressões de um ícone") fala de uma 
autoconstrução de uma persona, que evoca uma imagem cosmológica do martírio, construída através de suas pinturas e fotografias.

O trabalho de Kahlo pode ser entendido como uma reflexão e uma extensão de seu sofrimento e corpo ferido, mas também como um retrato de um país como uma ferida eternamente aberta. As pinturas de Frida são mais autorreferenciais e autorreflexivas, e algumas delas mostram sua consciência política. Como Frida Kahlo se concebeu nascida com a revolução, ela sempre procura refletir e transcender este evento central na história do México. Deve ser lembrado que ela se tornou comunista quando tinha vinte anos. Ela recebeu Trotsky em sua casa, antes de ele se mudar para alguns quarteirões da Casa Azul. Eles tiveram um caso, pouco antes de seu assassinato em 1937. Embora, Frida Kahlo não estivesse completamente de acordo com a decisão de Diego Rivera de trazer Trotsky para o México, ela foi durante toda a sua vida Stalinista. Ao final da sua vida, Frida Kahlo dedicou sua vida e obra à luta comunista.

\section{FRIDA KAHLO E O SURREALISMO}

A relação de Frida Kahlo com o surrealismo começou quando André Breton viajou para o México, 1938 e se apaixonou pelo trabalho de Frida. Apesar das declarações 
dela, dizendo que ela não pinta sonhos, mas sim a realidade. Enquanto Breton a considerava uma "surrealista autoinventada", quase como uma surrealista nata, Kahlo não se via como parte totalmente integrante do movimento, ela expressava seus sentimentos mais íntimos, mas não gostava de mistificá-los. Em sua biografia, Hayde Herrera, declara:

"I never knew I was a surrealist", she said, "till André Breton came to Mexico and told me I was". Increasingly as the years went on, she rejected the Surrealist label: "I never painted dreams," she pointed out. "I painted my own reality". (HERRERA, 2002, p. 124)

Apesar da negação, Herrera nota que o Surrealismo operou uma grande transformação no trabalho de Frida Kahlo e permitiu que ela aprofundasse a sua fantasia, que estava intrinsicamente ligada à sua cultura nativa. Logo após seu encontro com Breton, ela foi convidada par expor na galeria do então surrealista Julien Levy, em Nova lorque. Essa exposição teve um tremendo impacto na carreira de Frida Kahlo, diversos jornais escreveram elogiando seu trabalho. Após esta primeira exposição, Frida Kahlo viaja para Paris, onde faria uma outra exposição, organizada por Breton. Mas quando ela é tomada de surpresa ao saber que nada havia sido organizado para a exposição. Em sua carta à Nickolas Muray, fotografo norte-americano de 
origem Húngara, seu amante por algum tempo, ela expõe sua revolta:

Until I came the paintings were still in the custom house, because the $s$. of a b. Breton didn't take the trouble to get them out... So I had to wait days and days just like an idiot till I met Marcel Duchamp (marvelous painter), who is the only one who has his feet on the earth, among all this bunch of coocoo lunatic sons of bitches of the surrealists... Well, after things were more or less settled as I told you, a few days ago Breton told me that the associated of Pierre Colle, an old bastard and son of a bitch, saw my painting and found that only two were possible to be shown, because the rest are too "shocking" for the public! I could kill that guy and eat it afterwards... (HERRERA, 2002, p. 119)

A exposição foi um sucesso, apesar de Frida Kahlo não concordar totalmente com os objetos de Breton trazidos do México. Herrera aponta que houve um reconhecimento generalizado da maior parte dos pintores franceses: Joan Miró, Kandinsky, Picasso, Tanguy, Paalen e grandes personalidades do Surrealismo. De todos os quadros de Frida Kahlo "What the water gave me" seria o mais surrealista. O quadro apresenta elementos bem característicos da pintura de Frida Kahlo, inclusive ela utiliza outras pinturas, mas como miniatura, como por exemplo, o quadro "Two Nudes in a Forest", pintado em 1939. Outro exemplo é a imagem do casamento dos pais, 
também utilizada em outra obra de 1936, "My grandparents, my parentes, and Me". E, finalmente, outro exemplo é "My dress Hangs Here" de 1933-1938.

Dessa forma, podemos perceber que o quadro "What the Water Gave Me" poderia ser entendido como uma colcha de retalhos ou uma colagem de vários outros quadros em myse-en-abyme. Breton quando viu o quadro pela primeira vez, disse que a sua pintura era como "a beribboned bomb" (uma fita ao redor de uma bomba), Teresa del Conde, no artigo "Frida Kahlo and Fridomania" apresenta-nos sua perspectiva sobre esse quadro e explica como Frida Kahlo pintou o retratou a partir de suas memórias da infância, de ver-se submersa em uma banheira. Outras obras de Frida Kahlo poderiam ser usadas para demonstrar o surrealismo de Frida Kahlo, trabalhos de 1927, como o "Portrait of Miguel N. Lira".

\section{VIRGINIA WOOLF E A LINGUAGEM SURREALISTA}

A linguagem dos romances de Virginia Woolf estava também em plena consonância com os movimentos de vanguarda, podemos compreender a forma como ela representa seus personagens a partir de múltiplos pontos de vista e diversos planos narrativos, como uma linguagem cubista. Mas em muitos momentos podemos 
ler as imagens de Woolf como quadros surrealistas. Como a banheira de Frida Kahlo, Woolf também utiliza alguns pontos de fuga a partir de um detalhe externo, liberando uma série de interpretações e associações. Poderíamos citar alguns momentos da escrita de Woolf que poderiam ser considerados quadros surrealistas, como por exemplo os sonhos de Rachel Vinrace no romance The Voyage Out. Rachel apreende em seu sonho pequenos homens ou mulheres jogando cartas, que poderia equivaler a um quadro surrealista de Frida Kahlo. Outro momento surreal seriam as cenas de loucura Septimus Smith em que o personagem vê as fibras do seu corpo conectadas às folhas das árvores, em um outro momento Septimus vê o amigo Evan, que foi morto na guerra, surgir em um jardim de flores. A figura da velha mendiga, em Mrs. Dalloway, por si só representa uma imagem surreal, mas Woolf enfatiza o caráter insólito da cena, conferindo-Ihe de uma linguagem incompreensível, de uma sexualidade irreconhecível e sua canção dissolve as barreiras do tempo, lançando-a a um tempo primitivo e atemporal.

Em Orlando, a biography (1928), Woolf subverte o gênero da biografia, mesclando ficção e fatos históricos e reais baseados na vida de Vita Sackville-West, mas 
também recria fatos surreais em torno da personagem. O próprio enredo do romance pode parecer surreal ao leitor contemporâneo, Woolf retrata não apenas a vida de Orlando em torno de seu nascimento e morte, mas sim ao longo de três séculos. Após a grande geada e depois de se desiludir com Sasha, a princesa russa por quem se apaixona, Orlando dorme por 7 dias e 7 noites. Para escapar dessa decepção amorosa, Orlando refugia-se na Turquia, onde se torna um embaixador. Depois de passar por um transe, Orlando torna-se mulher. Woolf o faz de maneira muito natural, contudo ela desestabiliza a noção de realidade do leitor, quando rompe com as suas expectativas, a partir do insólito e do peculiar.

Flush, a biography (1933) segue as mesmas linhas de construção de Orlando, com um humor sagaz e afiado, Woolf apresenta um enredo extremamente surreal, a narrativa é contada a partir do ponto de vista do cachorro da poeta Elizabeth Barrett Browning. Ao contar a biografia de um Cocker Spaniel, Woolf satiriza os grandes biógrafos, tal como Leslie Stephen, além de denunciar a opressão feminina na era vitoriana, a partir do ponto de vista de Flush. O surreal e o insólito ocorrem ao personificar o cão e silenciar a heroína, Flush ocupa uma posição tão marginal, quanto à própria dona, mas acaba tendo mais agência e mais liberdade. 
Por fim, a peça Freshwater (1935), sobre a tia-avó de Virginia Woolf, a fotógrafa Julia Cameron, está repleta de cenas surreais, os diálogos, embora compreensíveis, são extremamente absurdos. Há cenas completamente insólitas, por exemplo, quando Ellen Terry, a atriz e modelo das fotos, alimenta um boto com seu anel. A peça fica ainda mais insólita com a chegada dos caixões e da rainha Vitória. Woolf com seu aguçado senso de humor encontrava, assim como Frida Kahlo, o surreal e o insólito nas cenas mais banais da vida diária. Embora o sofrimento seja enfatizado em ambas, não se pode esquecer o poder subversivo do humor em suas obras.

\section{CONSIDERAÇÕES FINAIS}

Espero ter demonstrado como essas duas artistas diferentes, com diferentes percepções, estavam questionando e rompendo com a tradição, revolucionando as formas de representação e ampliando as fronteiras de gênero e identidade. As duas estavam refletindo sobre o processo criativo e estavam criando uma forma inovadora para representar suas visões. Elas transformaram sua dor em arte, elas queriam revolucionar o mundo e isso começaria a partir dos reinos de suas próprias casas. Ao romper com a tradição patriarcal, elas também estavam refletindo sobre sua própria 
herança, procurando suas raízes, pensando em suas mães literárias e artísticas.

Pode-se perceber que ambas estavam conscientes da forma como se apresentavam ao mundo por meio de suas obras e das imagens por meio das fotografias veiculadas em diversos meios. Woolf, que detestava posar ou ser fotografada, aparece de diversas maneiras: glamourosa, como celebridade da sociedade britânica, jovem, frágil, etérea, apolítica. Em outras vezes, sua imagem é de uma feminista aterrorizadora, quando está atrelada à peça Who's afraid of Virginia Woolf, de Edward Albee. Frida Kahlo, ao contrário, acostumada às lentes do pai, apruma o corpo frente à câmera, parece destemida, segura, por vezes, imbatível.

Ambas utilizaram o diário como forma de construção de uma persona pública. Ambas ficcionalizaram o sofrimento, seja por meio da escrita ou por meio da pintura, no caso de Frida Kahlo. É possível perceber nessas obras uma certa performance do sofrimento, uma teatralização ou encenação do mesmo frente a um público que compartilha e purifica suas emoções.

Tanto Virginia Woolf, quanto Frida Kahlo passaram longos períodos reclusas e solitárias na cama e transformaram esse exercício da escrita em arte, como uma tarefa de 
autorreflexão e recriação. A impossiblidade de locomoção, o estar "still" e "ill" possibilitou um espaço para a imaginação, enquanto o corpo estava paralizado, a mente seguia em seu processo de criação constante. Frida Kahlo trocou os pés por asas aladas; Woolf durante toda a vida, entre períodos de desestabilidade mental e fragilidade corporal, refletiu e escreveu sobre a literatura, não apenas sobre suas mães literárias, mas também sobre seus pais literários.

Ao final desse trabalho, deixamos mais questionamentos do que respostas: Os diários podem ser considerados como obras de arte? Até que ponto há uma dramatização consciente da escrita de ambas que aponta para a construção de uma persona pública? Realmente, pode se falar em uma performatividade do sofrimento em suas obras?

\section{REFERÊNCIAS}

BELL, Quentin. Introduction. In: BELL, Anne Olivier (Ed.). The Diary of Virginia Woolf. Vol. I. 1915-1919.

CASANOVA, Rosa. Images and Impressions of an Icon. In: CASANOVA, Rosa et al. Frida's Frida. Ciudad de Mexico: Citi, p. 93-132, 2007. CONDE, Teresa del. Frida Kahlo and Fridomania. In: CASANOVA, Rosa et al. Frida's Frida. Ciudad de Mexico: Citi, p. 25-85, 2007. CORTANZE, Gérard. Frida Kahlo: The Gisèle Freund Photographs. New York: Abrams, 2013.

FUENTES, Carlos. Introduction. In: The Diary of Frida Kahlo: An intinmate self-portrait. New York: Abrams, 2005. 
FRANCO, Maria Teresa. Frida Kahlo: Self-portrait in Ink. In: Frida's Frida. Mexico City: Citi, p. 141-170, 2007.

HERRERA, Hayden. Frida Kahlo: The Paintings. New York: Harper Perenial, 2002.

FREUND, Gisèle. Gisèle Freund Photographer. Foreword Christian Caujolle. Tradução de JohnShepley. New York: Harry Abrams, 1985. KAHLO, Frida. The Diary of Frida Kahlo: An intinmate self-portrait. Introduction of Carlos Fuentes. New York: Abrams, 2005.

KAHLO, Frida. Frida's Frida. Mexico City: Citi, 2007.

LEE, Hermione. Introduction. In: WOOLF, Virginia. On Being III. Massachusetts: Paris Press, 2012.

LOWE, Sarah M. Essay and Commentaries. In: The Diary of Frida Kahlo: An intimate self- portrait. Introduction of Carlos Fuentes. New York: Abrams, 2005.

MARCUS, J. Wrapped in the Stars and Stripes: Virginia Woolf in the U.S.A. South Carolina Review, v. 29, n. 1, 1996.

MIRKIN, Dina Comisarenco. Moon. Sun. Me?. In: Frida's Frida. Mexico City: Citi, 2007.

OLIVEIRA, Maria A. Virginia Woolf and Victoria Ocampo: A Brazilian Perspective. In: VANDIVERE, Julie; HICKS, Megan (Eds.) Virginia Woolf and her Female Contemporaries. South Carolina: Clemson University Press, 2016.

ORENSTEIN, Gloria. Frida Kahlo: Painting for Miracles. Feminist Art Journal, fall, p. 7-9, 1973.

SILVER, B. Virginia Woolf Icon. Chicago: University of Chicago Press, 1999. STELLWEG, Carla. Frida Kahlo. The camera seduced. Mexico City: La Vaca Independiente, 1992.

TORO, Alfonso. Frida Kahlo's Transpicturality Revisited: Transmedial Dispositives, Representation, and Anti-Representations. In: GERNALZICK, Nadja; PISARZ-RAMIREZ, Gabriele. (Org.). Transmediality and Transculturality. Heidelberg: Universitatverlag, p. 305-348, 2013. 
WOOLF, Virginia (1935). Freshwater: A Comedy. Lucio Rutuolo (Ed.). New York: Harvest Book, 1976.

WOOLF, Virginia. A Writer's Diary. Ed. Leonard Woolf. London: Harverst Book, 1982.

WOOLF, Virginia. Moments of Being. Ed. Jeanne Schulkind. London: Harverst Book, 1985.

WOOLF, Virginia. Mrs. Dalloway. London: Penguin Classics, 1992.

WOOLF, Virginia (1928). Orlando. London: Penguin Books, 1993.

WOOLF, Virginia (1915). The Voyage Out. London: Oxford University Press, 2009.

WOOLF, Virginia (1933). Flush, a biography. London: Vintage, 2011.

\section{Maria Aparecida de Oliveira}

Doutora pela Universidade Federal da Paraíba Faz parte do grupo de pesquisa: Kew, Grifes.

Email: mariaaoliv@yahoo.com

Lattes: https://lattes.cnpq.br/2889350069897138

ORCID iD: https://orcid.org/0000-0003-4815-7659 